\title{
Desvelando a interdisciplinaridade da ciência da informação: o enfoque dos alunos do PPGCI/UFMG
}

\author{
Alzira Karla Araújo da Silva \\ Doutoranda em ciência da informação PPGCI/UFMG. Professora assistente do DCI/UFPB. \\ E-mail: alzirakarla@gmail.com \\ Izabel França de Lima \\ Doutoranda em ciência da informação PPGCI/UFMG. \\ E-mail: belbibb@yahoo.com.br \\ Carlos Alberto Ávila Araújo \\ Professor adjunto da ECI/UFMG. Doutor em ciência da informação/UFMG. \\ E-mail: casal@eci.ufmg.br
}

\begin{abstract}
Resumo
Discute a interdisciplinaridade da ciência da informação $(\mathrm{Cl})$ na ótica dos alunos oriundos das diversas áreas do conhecimento que ingressaram no Programa de Pós-Graduação em Ciência da Informação (PPGCl) da Universidade Federal de Minas Gerais (UFMG) em 2007 e 2008, na perspectiva de alcançar em suas práxis como pesquisadores, seja para revisar conceitos, seja para reforçar, refutar ou criar novas teorias. Metodologicamente, buscou-se uma abordagem quantiqualitativa para expressar a opinião dos pós-graduandos em Cl do PPGCI/UFMG. Os dados apontam que a informação como objeto de estudo, a fundamentação teórica da $\mathrm{Cl}$ e a sua interdisciplinaridade proporcionam um novo olhar dialógico da área. Os futuros cientistas da informação oriundos de outras áreas do conhecimento podem colaborar com a $\mathrm{Cl}$ identificando teorias e métodos que venham consolidar a interdisciplinaridade.
\end{abstract}

\section{Palavras-chave}

Interdisciplinaridade. Ciência da informação. Pós-graduação em ciência da informação.

\author{
Finding the interdisciplinarity of the \\ information science: the approach of the \\ students of the PPGCI/UFMG
}

\begin{abstract}
Interdisciplinarity of Information Science (IS) is discussed from the point of view of students from different areas of knowledge who joined the Post-Graduate Program in Information Science of Federal University of Minais Gerais State, in 2007 and 2008, for improvement of researchers in revising concepts, approving, denying or formulating new theories. An approach, both quantitative and qualitative, has been methodologically searched for in order to express the opinion of the post-graduate students in IS of the Program. The data point out that information as an object of study, i. e., the theoritical rationale of IS and its interdisciplinarity proportiate a new dialogue insight of this area. The future information scientists coming from other areas og knowledge are able to collaborate with IS by identifying theories and methods which may help to consolidate interdisciplinarity.
\end{abstract}

\section{Keywords}

Interdisciplinarity. Information science. Post-graduation in information science. 


\section{INTRODUÇÃO}

Desde as suas primeiras definições, ainda na década de 1960, a ciência da informação (CI) é tida como uma ciência interdisciplinar. Tal tipo de caracterização buscou reservar uma espécie de espaço de atuação que conjugasse saberes oriundos de áreas ligadas à representação do conhecimento (linguística, biblioteconomia, entre outras), às ciências sociais e às tecnologias da informação. Essa mesma definição, entretanto, serviu como argumento de legitimação, no campo, de pesquisadores oriundos de áreas tão diversas como a engenharia, a computação, a sociologia, a comunicação e a biblioteconomia, entre outras. Nesse tipo de arranjo "pragmático", a reflexão propriamente epistemológica envolvendo o uso de teorias e conceitos tomados de empréstimo a diversos campos do conhecimento, bem como o necessário rigor dos pesquisadores nessa transposição de métodos e na forma de pensar, acabou por, muitas vezes, ficar em segundo plano.

As discussões científicas a respeito da interdisciplinaridade costumam ressaltar que a utilização do prefixo "inter" não indica apenas uma pluralidade, uma justaposição de disciplinas; ela evoca um espaço comum, fator de coesão entre saberes diferentes que se afetam mutuamente. $\mathrm{Na}$ construção de áreas interdisciplinares, cada pesquisador aceita e se esforça para, fora do seu domínio e de sua linguagem técnica, aventurar-se em outros campos do conhecimento. Interdisciplinaridade não é construída na indisciplina, mas na argumentação estabelecida para mostrar as qualidades e a viabilidade das transmutações teóricas, metodológicas, conceituais e instrumentais.

Nesse sentido, autores como Borko (1968) e Saracevic (1970) desde cedo imaginaram para a CI um estatuto interdisciplinar - postura acompanhada, no Brasil, entre outros, por Pinheiro e Loureiro (1995), Targino (1995), Mostafa (1996), Gomes (2001) e Souza (2007). A ideia comum a esses autores é que a interdisciplinaridade no campo da CI se estabelece quando existem grupos de pesquisas consolidados atuando em duas ou mais áreas com os mesmos propósitos. Justifica-se a necessidade desse empreendimento ao se considerar que a CI, por se preocupar com a produção, organização e distribuição da informação para as mais diversas áreas do conhecimento, constitui-se fronteiriça, tecendo relações com essas outras áreas do conhecimento.

Com a motivação advinda de tais questões, buscouse discutir suas implicações a partir de alguma situação concreta, específica, relacionada aos diferentes perfis profissionais, disciplinares e teóricos, existentes no campo da CI. Para tanto, buscou-se investigar as razões da escolha, por parte de mestrandos e doutorandos oriundos de diversas áreas do conhecimento, de desenvolver suas pesquisas no âmbito do Programa de Pósgraduação da Escola de Ciência da Informação da Universidade Federal de Minas Gerais (PPGCI/ ECI/UFMG). Dessa forma, procurou-se identificar a forma como esses mestrandos e doutorandos conheceram a área de CI, como enxergam as relações entre a CI com suas áreas de origem e como compreendem as possíveis contribuições da CI para a concretização de suas pesquisas.

Considerando as reflexões sobre interdisciplinaridade na CI, geradas no intercurso das disciplinas "Fundamentos Teóricos da Informação" e "Teoria do Conhecimento em Ciência da Informação" no PPGCI/UFMG, foi desenvolvido um estudo analítico-interpretativo, com abordagem quantiqualitativa, a partir da aplicação de um questionário para a coleta de dados e da utilização de categorias analíticas para a análise dos dados coletados.

\section{A INTERDISCIPLINARIDADE NA CI: REVENDO UMA VELHA QUESTÃO}

A discussão sobre o que vem a ser a "interdisciplinaridade" surge em meados do século XX e se relaciona com algo que vai além de uma só disciplina, uma transgressão de fronteiras 
disciplinares. Sua origem é identificada com o movimento de ir além de uma disciplina:

[...] a interdisciplinaridade consiste em um trabalho em comum, tendo em vista a interação de disciplinas científicas, de seus conceitos básicos, dados, metodologia [...]. A prática interdisciplinar reúne forças para se enfrentarem os limites e barreiras colocados pela desastrosa fragmentação do saber, decorrente de sua divisão em conteúdos estanques [...] (GONÇALVES, 1991, p.1).

A interdisciplinaridade surge como uma reação à existência de disciplinas distintas, isoladas. $\mathrm{O}$ primeiro passo, pois, para se compreender a interdisciplinaridade é entender como se deu o processo de construção de disciplinas, de "fragmentação do saber", de "divisão [do conhecimento] em conteúdos estanques”.

De acordo com França (2002a, p.17), disciplinas "são domínios do conhecimento já consolidados, são campos científicos que já estabeleceram uma tradição". A disciplina é, assim, um "pedaço" específico do conhecimento, do conjunto de saberes da humanidade, que se torna singular, particular, distinto, seja em relação aos conceitos que postula/utiliza, ao conjunto de informações e dados que contém, às metodologias que empreende ou ao conjunto de fatos e fenômenos do mundo aos quais recorre.

Não é possível precisar quando, na história da humanidade, teve origem a fragmentação do saber. Sabe-se, contudo, que, nas eras primitivas, précivilizadas, o conhecimento humano era total, isto é, não distinguia tipos de saberes nem hierarquia entre eles. Era um conhecimento tácito e essencialmente colado à experiência, vinculado aos elementos com os quais cada ser humano se relacionava. Essa situação primeira é descrita por Pierre Lévy e Michel Authier (1995, p.89-90) a partir da metáfora da "árvore mística":

Quando os humanos ainda viviam no Paraíso, havia no meio do Jardim uma árvore mística cuja vida era misteriosamente ligada aos seus feitos e gestos. Cada nascimento de um pequenino homem acrescentava uma radícula à árvore e cada morte fazia desaparecer uma fibrila de suas raízes. [...] A árvore crescia com a humanidade. [...] Assim, todos os humanos vivos formavam as raízes da árvore mística e todos eram dela jardineiros [...].

A metáfora ilustra certo momento da humanidade em que o saber e o conhecimento eram socialmente compartilhados sem que existisse posse de saberes por parte de uns ou de outros, ou hierarquias ou divisões destes saberes. Não existia ainda uma especialização, uma diferenciação, assim como não existia uma divisão do trabalho. É exatamente com a organização dos homens em agrupamentos ou sociedades (ainda que em graus até mesmo rudimentares de organização, como as tribos, ou em graus mais complexos, como nas primeiras cidadelas) e a divisão das tarefas entre os vários membros destas sociedades que se começa a pensar na ideia de conhecimentos úteis, conhecimentos diferenciados para situações específicas. Lévy e Authier (1995, p.90-91) metaforizam esses acontecimentos com a ideia da "queda da árvore mística":

Mas chegou uma estação (nesta época, as geleiras estavam bem ao norte) em que a brisa da noite trazia mensagens inéditas, incompreensíveis. Algo havia imperceptivelmente mudado no ar do Jardim. Uma fenda crescia entre o espaço e o tempo. Os Deuses mudaram de feição. Não era mais o Paraíso. [...] Uma casta estabeleceu-se acima dos outros homens. Com uma grande quantidade de escravos, ela dirigia as escavações de longos canais de irrigação, a ereção de diques contra a cólera e o transbordamento dos rios. Os administradores faziam subir as muralhas, templos, pirâmides e torres para parar o tempo, eternizar a glória dos reis e contemplar mais de perto as estrelas. $\mathrm{Na}$ sombra dos palácios, os escribas gravavam em suas estantes o crescimento das tropas, o registro dos escravos e a contagem dos grãos nos silos. Possuídos pelo 
jogo de um incessante cálculo, os escribas quiseram também contar o saber: desenharam, então, uma árvore do conhecimento do seu campo e se embriagaram com este seu novo poder.

A complexificação das atividades humanas leva à necessidade de ampliação das atividades desenvolvidas, a um grau tal que se torna impossível que alguém detenha todos os conhecimentos "estocados" de determinada comunidade. E, no desenvolvimento de atividades mais específicas por parte de cada um (o desenvolvimento de técnicas, de procedimentos, de estratégias), começa a aumentar a quantidade de conhecimentos e saberes sobre cada uma destas atividades, de modo que cada ser humano já não executa mais uma tarefa da mesma forma (ou com a mesma otimização) que outro, não apenas por diferenças de habilidades ou experiências, mas também pelo acesso a determinadas informações e saberes. Ainda de acordo com Lévy e Authier (1995, p.101),

se é justo dizer que cada um sabe, é preciso imediatamente acrescentar que ninguém sabe tudo. Em relação à imensidão de saberes que circulam, crescem e se multiplicam entre os humanos, cada um ignora infinitamente mais coisas do que tem noção.

O processo de especialização, de aprofundamento do conhecimento sobre algo (uma atividade qualquer) por parte de alguém é acompanhado pelo processo de não conhecimento de outras atividades e saberes por parte deste mesmo alguém, que delega a outra pessoa a realização de determinada atividade. Começa a haver pessoas que não detêm todos os conhecimentos e saberes relacionados à sua experiência, e que precisam, portanto, de um especialista, isto é, daquele que possui os saberes relacionados a uma atividade específica.

$\mathrm{Na}$ literatura sobre história e filosofia da ciência (ALFONSO-GOLDFARB, 1994; ALVES, 1982; KRAGH, 1989; OMNÉS, 1996; SERRES, 1989), esse momento inicial descrito por Lévy e Authier
(1995) como a "árvore mística" representa o momento histórico em que a única forma do homem estocar e elaborar conhecimentos é aquela conhecida como "senso comum". Trata-se de uma forma de conhecimento do mundo que surge da necessidade imediata do ser humano de entender a realidade e desempenhar determinada tarefa. Constrói-se a partir da intuição e da experiência, consolidando-se pela imitação e pela construção de uma tradição.

A necessidade do homem de uma compreensão mais aprofundada do mundo, bem como a necessidade de precisão para a troca de informações, acaba levando à elaboração de sistemas mais estruturados de organização do conhecimento. Gérard Fourez destaca que, no início, os homens se comunicavam a partir de uma linguagem que utilizava um código restrito, em que os objetos do mundo são descritos sem uma preocupação com o alcance das descrições, não há uma reflexão elaborada. É a linguagem do dia a dia, "útil na prática e que não leva adiante todas as distinções que se poderia fazer para aprofundar o meu pensamento" (FOUREZ, 1995, p.18). Mas, com o tempo, passaram a desenvolver um código "elaborado", com o objetivo de tornar as noções mais precisas e sistematizar os campos de conhecimento. Aqui se tem a origem dos "conceitos", noção fundamental para a formação dos campos disciplinares. Representantes da Teoria do Conceito, como Dahlberg (1978), enfatizam a importância dos conceitos para a consolidação de áreas específicas do conhecimento e o estabelecimento de suas fronteiras.

De acordo com outro autor, "a ciência tem as suas origens nas necessidades de conhecer e compreender (ou explicar), isto é, nas necessidades cognitivas" (MASLOW, 1979, p.206). De um conhecimento difuso, espalhado, assistemático e desorganizado, passa-se a um trabalho de arranjo segundo certas relações, de disposição metódica.

O processo de gradual implementação do processo histórico da Modernidade e de sua forma de 
conhecimento mais legitimada, a ciência, dá-se, assim, com o concurso fundamental da ideia de disciplina. Ao longo do século XX começam a surgir diversas críticas ao projeto da Modernidade (ADORNO; HORKHEIMER, 1990) e à ciência moderna (HABERMAS, 1987). Dentre as diversas críticas, destaca-se a ideia da ciência convertida em instrumento de dominação, de manipulação e alienação, de subserviência a interesses políticos e militares, de legitimação de sociedades autoritárias e desumanas. No bojo do conjunto mais geral de críticas ao modo moderno de se fazer ciência (a separação entre sujeito e objeto, a busca da neutralidade científica, entre outros), apareceu, ao longo da primeira metade do século XX, a crítica às formações disciplinares.

O termo interdisciplinaridade, de forma geral, representa qualquer tentativa de se estabelecer alguma ligação ou integração entre diferentes disciplinas, isto é, realiza um movimento de superação da monodisciplinaridade, que é o que acontece quando uma disciplina atua de forma isolada, operando apenas com seus próprios conceitos, métodos e objetos de estudos.

Essa ligação e integração pode se dar de várias formas. A primeira delas é "uma simples justaposição, num trabalho determinado, dos recursos de várias disciplinas" (JAPIASSU, 1976, p.72), isto é, quando um objeto é estudado por várias disciplinas que permanecem sem contato entre si. Trata-se da multidisciplinaridade. Essa mesma justaposição de disciplinas, quando compreende algum esforço de intercâmbio e cooperação entre elas, passaria a representar um estágio superior, definido por Paim (2002) como sendo um processo "pluridisciplinar".

Já a interdisciplinaridade

consiste em um trabalho em comum, tendo em vista a interação de disciplinas científicas, de seus conceitos básicos, dados, metodologia [...]. A prática interdisciplinar reúne forças para se enfrentarem os limites e barreiras colocados pela desastrosa fragmentação do saber, decorrente de sua divisão em conteúdos estanques [...] (GONÇALVES, 1991, p.1).

Nesse estágio, as disciplinas interagem e passam a depender umas das outras, num processo dinâmico. Esse processo, contudo, pode se dar de duas formas. Uma, em que

as disciplinas permutam informações. Contudo, nessas trocas, não há reciprocidade. E a cooperação propriamente metodológica é praticamente nula. As disciplinas que fornecem informações a uma outra fazem-no a título de disciplinas 'auxiliares', permanecendo, relativamente a ela, numa situação de dependência ou de subordinação (JAPIASSU, 1976, p.81).

Nesse caso, tem-se uma interdisciplinaridade linear ou cruzada, em que "o paradigma de uma disciplina é imposto a outras disciplinas do mesmo nível" (PAIM, 2002, p.1). A outra forma é a interdisciplinaridade estrutural, que seria a interdisciplinaridade propriamente dita, a

integração real das disciplinas num projeto [...] [com] esforços de superação de barreiras paradigmáticas e de interação de equipes (PAIM, 2002, p.1).

Nesse processo,

[...] duas ou mais disciplinas ingressam, ao mesmo tempo, num diálogo em pé de igualdade. Não há supremacia de uma sobre as demais. As trocas são recíprocas. O enriquecimento é mútuo. São colocados em comum não somente os axiomas e os conceitos fundamentais, mas os próprios métodos. Entre elas há uma espécie de 'fecundação recíproca' [...] Trata-se de um tipo de interdisciplinaridade que não se efetua por simples adição nem tampouco por mistura. O que há é uma combinação das disciplinas, correspondendo ao estudo de novos campos de problemas, cuja solução exige a convergência de várias disciplinas, tendo em vista levar a efeito uma ação informada e eficaz (JAPIASSU, 1976, p.81). 
Por fim, a transdisciplinaridade representa, conforme Piaget,

uma etapa superior, que não se contentaria em atingir interações ou reciprocidade entre pesquisas especializadas, mas que situaria essas ligações no interior de um sistema total, sem fronteiras estabelecidas entre as disciplinas (JAPIASSU, 1976, p.75).

Mais do que o rompimento de fronteiras entre as disciplinas, a verdadeira abordagem transdisciplinar romperia com o próprio paradigma disciplinar - a partir do que se recupera o sentido do prefixo trans, "movimento para além de". Enquanto na interdisciplinaridade determinado tema ou objeto é apreendido e tratado por diferentes ciências, sem que haja um deslocamento ou uma alteração no referencial teórico destas ciências,

a transdisciplinaridade, por sua vez, compreenderia um movimento diferente: uma determinada questão ou problema suscita a contribuição de diferentes disciplinas, mas essas contribuições são deslocadas de seu campo de origem e entrecruzam-se num outro lugar - em um novo lugar. São esses deslocamentos e entrecruzamentos - esse transporte teórico que provocam uma iluminação e uma outra configuração da questão tratada. É esse tratamento híbrido, distinto, que constitui o novo objeto (FRANÇA, 2002b, p.17-18).

As distinções entre pluri, multi, inter e transdisciplinaridade têm sido trabalhadas, atualmente, por Pombo (1994), para quem a pluri ou multidisciplinaridade pressupõe estabelecer algum mínimo de coordenação; a interdisciplinaridade exige uma convergência de pontos de vista; e a transdisciplinaridade remete a uma fusão unificadora. Em meio a essa gradação, a interdisciplinaridade pode ser considerada como uma integração interna e conceitual que rompe a estrutura de cada disciplina para construir uma axiomática nova e comum a todas elas, com o fim de dar uma visão unitária de um setor do saber. É o intercâmbio mútuo e a integração entre várias ciências, cuja cooperação resulta no enriquecimento recíproco (POMBO, 1994).

A interdisciplinaridade ultrapassaria, nesse sentido, a pluridisciplinaridade, porque vai além da análise e confrontação das conclusões, elaborando uma síntese em nível de métodos, leis e aplicações; preconizando um regresso ao fundamento da disciplina, revelando como a identidade do objeto de estudo se complexifica por meio dos diferentes métodos das várias disciplinas e explicitando a sua problematicidade e mútua relatividade (POMBO, 1994, 2003). Para ser efetiva, atualiza-se no campo das abstrações teóricas, do estabelecimento das metodologias, nas intervenções que as disciplinas promovem no social (GOMES, 2001).

Morin (1996) e Santos (2003) apontam haver cada vez mais necessidade de que as disciplinas científicas, em seu processo constante e desejável de interpenetração, fecundem-se mutuamente. Nesse processo de troca e reciprocidade, a interdisciplinaridade é um método de pesquisa e de ensino suscetível de fazer com que duas ou mais áreas do conhecimento interajam entre si. Para Japiassu e Marcondes (1991), esta interação pode ir da simples comunicação das ideias até a integração mútua dos conceitos, da epistemologia, da terminologia, da metodologia, dos procedimentos, dos dados e da organização da pesquisa. Ela torna possível a complementaridade dos métodos, dos conceitos, das estruturas e dos axiomas sobre os quais se fundam as diversas práticas científicas.

O objetivo utópico da interdisciplinaridade é a unidade do saber, elaborando um formalismo suficientemente geral e preciso que permita exprimir, em linguagem única, os conceitos, as preocupações, os contributos de um número maior ou menor de disciplinas que, de outro modo, permaneceriam fechadas nas suas linguagens especializadas, facilitando o intercâmbio. A compreensão recíproca é um dos fatores essenciais de uma integração dos saberes (DELATTRE, 1990). 
As discussões sobre a natureza interdisciplinar da CI nem sempre são efetuadas nesses termos. Uma das visões sobre essa questão ressalta a ideia de um possível estado de fragilidade teórica da CI a partir de sua construção edificada em correntes de pensamento heterogêneas, algumas até dicotômicas (PINHEIRO; LOUREIRO, 1995). Já Mostafa (1996, p.2) reforça a ideia do caráter interdisciplinar quando considera a CI como "uma nova configuração temática", ressaltando que ela "nasce no entremeio contraditório entre as disciplinas sociais tecnológicas e no espaço deixado por recortes já instituídos pela biblioteconomia e demais ciências sociais". Esse caráter relacional demonstra a interdisciplinaridade da CI. Porém, "a interdisciplinaridade efetiva é aquela que se atualiza no campo das abstrações teóricas, do estabelecimento das metodologias, mas também nas intervenções que as disciplinas promovem no social" (GOMES, 2001, p.8). Assim, cabe analisar as disciplinas que buscam expandir suas bases teóricas, percebendo em que medida a CI está inserida em seu agir, observando pontos de interseção, troca e convergência.

Targino (1995, p.13) também defende a CI como uma área na qual a interdisciplinaridade possui um caráter norteador, relacionando-se com diversos campos que "[...] são também irremediavelmente interdisciplinares, por conservarem como objeto de estudo a informação [...]." Para a autora, esse perfil epistemológico irrefutável da CI a faz emergir como "metaciência" ou "supraciência", ultrapassando fronteiras para interagir com outras ciências. Em contrapartida, Souza (2007, p.67) entende a interdisciplinaridade como método de ensino e pesquisa, ou seja, instrumento intelectual de abordagem de fatos sociais como a "leitura, comunicação, conhecimento, educação, memória, política e economia", ressaltando-os como fontes dos múltiplos objetos da CI.

O estatuto interdisciplinar da CI vai gradativamente adquirindo novas configurações conforme os diversos debates e questões colocadas em cada época e contexto. Disciplinas e subáreas do campo e seus problemas, que exigem soluções de outras áreas, promovem transformações interdisciplinares e, inversamente, as novas relações epistemológicas vão modificando o território da área (PINHEIRO, 2002). Nesse sentido, é preciso enfrentar o desafio ressaltado por Gomes (2001) de problematizar o diálogo interdisciplinar. A autora constata a importância de estudar não apenas os movimentos que a CI faz em direção às outras disciplinas científicas, mas também de ver, nessas disciplinas, se existe ou não movimentos em direção à CI. Só assim seria possível perceber se, afinal, existe uma relação de reciprocidade, de afetamento mútuo, característico da interdisciplinaridade.

\section{PERCURSO METODOLÓGICO}

O conjunto de questões anteriormente levantadas conduziu ao interesse pela problematização da seguinte questão: assumindo-se a perspectiva da interdisciplinaridade, que contribuições a CI ofereceria para o estudo de pesquisadores oriundos de outras áreas de conhecimento? Para responder à questão, realizou-se pequeno estudo empírico com mestrandos e doutorandos do PPGCI/UFMG. Optou-se por empreender um estudo analíticointerpretativo, desenvolvido sob uma abordagem quantiqualitativa, com o objetivo de analisar, especificamente, o porquê de estudantes do programa, oriundos de outras áreas do conhecimento, terem escolhido a CI para desenvolver seus trabalhos. Correspondendo ao que se espera de uma pesquisa quantiqualitativa, foram privilegiados, na coleta e análise de dados,indicadores, representações, atitudes e opiniões dos componentes.

\section{Universo e amostra da pesquisa}

O universo da pesquisa foi composto por 46 alunos regularmente matriculados nas disciplinas "Fundamentos Teóricos da Informação" (FTI) e "Teoria do Conhecimento em Ciência da Informação" (TCCI) do PPGCI/UFMG, que ingressaram no programa nos anos de 2007 e 2008. 
$\mathrm{Na}$ disciplina TCCI, exclusiva para alunos do doutorado, havia, na ocasião da pesquisa, 21 alunos. Na disciplina FTI, eram 33 os matriculados - 25 mestrandos e oito doutorandos (todos também matriculados em TCCI). Desse universo, foram selecionados os graduados em qualquer outra área que não a de biblioteconomia e ciência da informação. Participaram, no total, 19 pesquisadores (sete mestrandos e 12 doutorandos).

\section{Instrumento de coleta e apresentação dos dados}

O instrumento utilizado para a coleta de dados foi o questionário, com perguntas abertas e fechadas, dividido em duas partes. A primeira conteve questões para caracterização do perfil dos alunos. A segunda foi composta de perguntas relacionadas à temática da interdisciplinaridade. O questionário foi aplicado no mês de abril de 2008. Para apresentar os dados, organizaram-se quadros para a sistematização dos dados quantitativos e categorias analíticas para a compreensão das respostas e argumentos obtidos. Algumas falas representativas são utilizadas para ilustrar as categorias trabalhadas. Para manter o anonimato dos alunos, eles foram identificados da seguinte forma: mestrandos (M1, M2, M3..., M7) e doutorandos (D8, D9, D10..., D19).

\section{CIÊNCIA DA INFORMAÇÃO E AS RELAÇÕES DE SENTIDOS}

Os resultados da pesquisa são apresentados a seguir em dois momentos: o primeiro com o perfil dos sujeitos; o segundo com as opiniões dos entrevistados sobre o modo como conheceram a CI, a relação da CI com a sua área de formação e a contribuição da CI para seu objeto de estudo.

\section{Perfil dos sujeitos}

Para delinear as áreas de origem dos mestrandos e doutorandos no PPGCI/UFMG e relacioná-las com a interdisciplinaridade, identificou-se sua formação acadêmica, apresentada no quadro 1.

Entre os mestrandos, observa-se que as maiores frequências de área de graduação se dão na administração, ciência da computação/informática (três alunos cada uma) e comunicação social/ jornalismo e engenharia elétrica (dois alunos cada uma). No caso da área de administração, é possível identificar uma interface importante, uma vez que o PPGCI/UFMG abriga uma linha de pesquisa em

QUADRO 1

Área de graduação dos mestrandos e área de mestrado dos doutorandos

\begin{tabular}{|c|c|c|c|}
\hline Área de graduação dos mestrandos & $\mathrm{N}^{\mathrm{a}}$ alunos & $\begin{array}{c}\text { Area de mestrado dos } \\
\text { doutorandos }\end{array}$ & $\mathrm{N}^{\circ}$ alunos \\
\hline Administração & 3 & Ciência da Informação & 7 \\
\hline Ciència da Computação /Informática & 3 & Administração & 3 \\
\hline Comunicação Social - Jornalismo & 2 & Engenharia Elétrica & 1 \\
\hline Engenharia Elétrica & 2 & Antropologia & 1 \\
\hline Tecnologia em Processamento de Dados & 1 & & \\
\hline Filosofia & 1 & & \\
\hline Engenharia Mecânica & 1 & & \\
\hline Direito & 1 & & \\
\hline Design Gráfico & 1 & & \\
\hline Comunicação Social - Relaçōes Públicas & 1 & & \\
\hline Ciências Sociais & 1 & & \\
\hline Ciências Económicas & 1 & & \\
\hline Ciências Contábeis & 1 & & \\
\hline Total & 19 & Total & 12 \\
\hline
\end{tabular}

Fonte: dados da pesquisa, 2008 
"gestão da informação e do conhecimento", que articula diversos conceitos e teorias do âmbito gerencial. Já a área de comunicação social/ jornalismo também possui uma relação muito próxima, uma vez que ambas trabalham na perspectiva dos suportes materiais do conhecimento humano. Essa proximidade se expressa, por exemplo, em instituições como a Universidade Federal da Bahia, a Universidade de São Paulo e a Universidade Federal do Rio Grande do Sul, nas quais as duas áreas estão institucionalmente juntas - seja como unidades de ensino ou como programas de pós-graduação unificados. Deve-se ressaltar que administração e comunicação social são, como a CI, ciências sociais aplicadas (conforme a classificação promovida, no Brasil, pelo Conselho Nacional de Desenvolvimento Científico e Tecnológico (CNPq)) - , tendo, portanto, uma natureza próxima em relação à diversidade que caracteriza a atividade científica.

Já as áreas de ciência da computação/informática e engenharia elétrica, pertencentes ao campo das ciências exatas, possuem relativo grau de aproximação principalmente pelo caráter aplicado e técnico da CI, caráter esse impulsionado pelas tecnologias digitais em constante evolução desde o século anterior - muitas vezes denominadas "tecnologias da informação".

Quanto aos doutorandos pesquisados, destacamse o mestrado em ciência da informação (sete) e em administração (três). Esses dados mostram que parte considerável daqueles que obtiveram seu mestrado na área de CI, mesmo advindos de outras áreas, resolveram prosseguir sua formação no campo da CI no nível do doutorado.

Os autores que normalmente discutem o caráter interdisciplinar da CI costumam apresentar listas de disciplinas com as quais mais se dá a interlocução. Nessas apresentações, as áreas mais citadas são justamente comunicação social, ciências da computação, informática, administração, direito, filosofia e economia (BORKO, 1968; PINHEIRO, 2002; SARACEVIC, 1996; SMIT; TÁLAMO; KOBASHI, 2004; TARGINO, 1995). Tal leque indica relativa identificação entre as áreas normalmente listadas na literatura do campo e a realidade específica do PPGCI/UFMG.

\section{Opinião dos sujeitos}

A segunda parte do questionário centrou-se na opinião dos entrevistados sobre a forma como conheceram a CI, sobre a relação da CI com a sua área de formação e ainda a contribuição da CI para seu objeto de estudo. $\mathrm{Na}$ primeira questão, as diversas respostas foram agrupadas a partir de eixos semelhantes, possibilitando categorizá-las, conforme mostra o quadro 2.

A categorização dos discursos permitiu identificar que o tipo mais frequente de resposta sobre como conheceram a área de CI foi a indicaşão de alguém (11). A indicação se fez principalmente por

\section{QUADRO 2}

Forma como os sujeitos conheceram a CI

\begin{tabular}{|c|c|}
\hline Categorias & $\mathbf{N}^{\circ}$ Alunos \\
\hline Indicação de alguém & 11 \\
\hline Leitura de textos da CI & 3 \\
\hline Curso de especialização da ECI/UFMG & 3 \\
\hline Pesquisa sobre áreas de pós-graduação & 1 \\
\hline Propagandas & 1 \\
\hline Total & 19 \\
\hline
\end{tabular}

Fonte: dados da pesquisa, 2008 
professores, colegas e ex-alunos do PPGCI, conforme segue:

$\mathbf{M}_{7:}$ um professor da especialização em análise de sistemas sugeriu o mestrado em CI;

$\mathbf{D}_{8:}$ indicação de amigos pesquisadores;

$\mathbf{D}_{16}$ : através de conhecidos que fizeram a pósgraduação em CI.

Tais resultados evidenciam que os profissionais que fazem parte da CI disseminam a noção de interdisciplinaridade e possuem estreita relação com a pesquisa de Araújo et al. (2007) realizada com professores e pesquisadores de todas as faculdades de biblioteconomia e CI do Brasil, na qual 93,5\% consideram a CI interdisciplinar, alegando que o seu conteúdo tem relações com diferentes áreas do conhecimento e porque outras áreas precisam dela.

O segundo tipo de resposta mais frequente foi a leitura de textos sobre CI (três alunos), o que demonstra que sua produção científica, acessada por pessoas de outras áreas, vem atraindo atenção diversa. A pesquisa de Araújo et al. (2007) apontou que, para os pesquisadores brasileiros, os autores mais relevantes da CI são Saracevic, Lancaster, Borko, Pinheiro, Barreto, Miranda, Shera, Capurro e Le Coadic. Muitos deles produzem e publicam questões de interesse mais amplo do que aqueles especificamente ligados à CI - por exemplo, relacionados às novas tecnologias, à sociedade da informação, à epistemologia social, entre outros. A maioria também discute questões epistemológicas e é constituída de autores de alguns dos textos lidos também pelos alunos do programa:

$\mathbf{M}_{2}$ : com a sugestão de leitura de textos da CI, feita por um amigo, que considerou estudos da área pertinentes a minhas inquietações e reflexões;

$\mathbf{D}_{19}$ : o primeiro contato com a CI foi através da leitura do texto do Saracevic durante o mestrado.

Quanto à realização de pósgraduação lato sensu na ECI/ UFMG (caso de três alunos), deve-se lembrar que, nos resultados do quadro 2 , foram identificados sete doutorandos mestres em CI. Tal fato permite perceber que, no âmbito da ECI/UFMG, em seus níveis de especialização, mestrado e doutorado, tem havido uma prática de formação continuada. Além disso, a divulgação institucional desses cursos parece ter impacto importante, como identificado em algumas falas:

$\mathbf{M}_{4}$ : Através do curso de pós-graduação (especialização) em gestão estratégica da informação - ECI/UFMG.

$\mathbf{D}_{11}$ : Encontrei o curso de especialização a partir de uma busca surgida da necessidade de conhecer melhor a questão da informação nas organizações e sua relação com a TI.

Já sobre a relação que os alunos de mestrado e doutorado acreditam existir entre sua área de origem e a CI, foram obtidas respostas que, uma vez categorizadas, resultaram em quatro ideias principais, apresentadas a seguir, no quadro 3.

QUADRO 3

\section{Relação da CI com a área de formação}

\begin{tabular}{|c|c|}
\hline Categorias & $\mathbf{N}^{\circ}$ Alunos \\
\hline Objeto da CI (informação) & 10 \\
\hline Interdisciplinaridade (teorias complementares e integrantes) & 5 \\
\hline Aplicação de tecnologias de informação no processamento da informação & 3 \\
\hline Não sabe, falta estudos sobre o tema & 1 \\
\hline Total & 19 \\
\hline
\end{tabular}

Fonte: dados da pesquisa, 2008. 
A resposta mais frequente foi considerar a informação como objeto de estudo (dez alunos) de sua área de origem e da CI, corroborando a ideia da informação como objeto de várias ciências (BORKO, 1968; SARACEVIC, 1996; TARGINO, 1995). A ideia de interdisciplinaridade (cinco alunos) entre as áreas vem reforçar tanto a importância que esse tipo de prática possui na contemporaneidade, quanto o reconhecimento da CI como um lugar de manifestação e acolhimento de posturas e práticas interdisciplinares. Já o interesse pela aplicação de tecnologias de informação no processamento da informação relaciona-se com o potencial da CI de contribuir com um tipo de conhecimento específico (sobre a informação) para práticas e teorias relativas às tecnologias da informação, numa perspectiva de complementaridade para a resolução de problemas de natureza complexa. Algumas falas ilustram o desdobramento específico destas questões:

$\mathbf{M}_{1:}$ Mesmo objeto - o tratamento da informação.

M4: [...] A ciência da informação complementa [a ciência da computação] com os métodos, processos e fluxos.

$\mathbf{M}_{5}:$ Tem tudo a ver por causa do objetivo/ objeto, considerando a informação como este objeto.

$\mathbf{M}_{\text {6: }}$ Por ter a CI um objeto dito "informação", que, do meu ponto de vista, é um objeto social, ou seja, histórico-cultural, e ainda ubíquo. Desta forma proporcionará um olhar diferenciado, o qual servirá de subsídios para um melhor e mais complexo entendimento próprio (meu entendimento).

$\mathbf{D}_{19:}$ Por entender que a CI é interdisciplinar, a relação se dá por pontos de contato com a administração. A CI permite compreender alguns fenômenos organizacionais não explicados pela administração.

As respostas tendem para o reforço da natureza interdisciplinar da CI. Contudo, conforme alerta Pinheiro (2002), é preciso haver a preocupação com o fortalecimento do campo, com o trabalho cooperativo entre pesquisadores para se aglutinarem temas, conceitos, métodos e teorias e para que o contato entre as áreas não seja limitado a simples suporte para tópicos pontuais ou empréstimos casuais.

Por fim, interrogados sobre a contribuição da CI para a construção dos objetos de estudo de suas pesquisas, os entrevistados levantaram opiniões que foram categorizadas em três ideias principais, apresentadas a seguir, no quadro 4 .

Os resultados revelam que a contribuição da CI para o foco de estudo dos mestrandos e doutorandos do PPGCI/UFMG está diretamente ligada a três vertentes básicas: fundamentos teóricos da informação, interdisciplinaridade e afinidade com 0 objeto de estudo. Isso se confirma quando se percebe a forte presença do caráter interdisciplinar da CI como justificativa para o ingresso de sujeitos de outras áreas do conhecimento na CI, a fim de

\section{QUADRO 4}

\section{Contribuição da CI para o objeto de estudo de pesquisadores oriundos de outras áreas}

\begin{tabular}{l|c}
\multicolumn{1}{c|}{ Categorização } & N $^{0}$ Alunos \\
\hline Bases teóricas para o estudo da informação & 15 \\
\hline Interdisciplinaridade da CI & 10 \\
\hline Afinidade com o objeto de estudo & 10 \\
\hline \multicolumn{1}{c|}{ Total de respostas } & 35 \\
\hline
\end{tabular}

* Questão com mais de uma resposta por respondente.

Fonte: dados da pesquisa, 2008. 
encontrar bases teóricas e metodológicas para construção de suas pesquisas. Eis algumas das falas:

$\mathbf{M}_{1}$ : A própria CI é o meu objeto de pesquisa.

$\mathbf{M}_{2}$ : A CI permite uma análise sobre necessidade de informação, demandas, relevância, tratamento, usos, o que pode contribuir com a interpretação sobre a função social do rádio, meu objeto de estudo, visto como sistema de informação.

$\mathbf{M}_{3}$ : A abertura para discutir o assunto da pesquisa (influência dos suportes materiais da informação nos processos de armazenamento e recuperação), além de teorias (suporte/ conteúdo).

$\mathbf{M}_{4}$ : O meu objeto de estudo é como a informação e os sistemas que a suportam podem manter a competitividade das organizações e suas estratégias empresariais. A CI contribuirá, como ferramenta, no entendimento do fluxo destas informações nas organizações (interno e externo).

$\mathbf{D}_{11}$ : Meu objeto de estudo é um objeto que pode ser "lido" por várias lentes, no entanto a minha opção de olhar pela lente da CI tem a ver com minha opção profissional de abraçar a CI como campo de pesquisa [...].

$\mathbf{D}_{14}:[\ldots]$ A CI contribui para entendermos melhor os meandros da informação, não apenas como dados a serem transmitidos, mas, principalmente, o que há por trás dela informação versus cultura versus sociedade.

$\mathbf{D}_{16}$ : As questões relativas ao conhecimento têm sido desenvolvidas pela CI e por isso têm uma grande contribuição para meu foco de estudo, que é a criação do conhecimento.

$\mathbf{D}_{19}$ : A grande contribuição da CI dar-se em razão da necessidade de aprofundar o estudo da informação e do conhecimento como recursos organizacionais para o desenvolvimento da vantagem competitiva.

A busca pela fundamentação teórica da CI mostra certa vontade de ampliar as possibilidades de olhar os distintos objetos, trazidos das áreas de origem dos alunos. Novas teorias e métodos surgem como possibilidades, em alguns casos, de complementação, em outros, de efetiva reestruturação dos conhecimentos acumulados até então. Entretanto, mais uma vez se vê a presença da ideia de interdisciplinaridade, aqui entendida também como a construção de um espaço (a CI) em que a prática do trabalho interdisciplinar pode ser feita - e mais, até estimulada. Tal ideia assemelha-se aos argumentos de Delattre (1990), para quem existe a necessidade de se elaborar um formalismo suficientemente geral e preciso que exprima, em linguagem comum, os conceitos, as preocupações, os contributos de um número de disciplinas que, de outro modo, permaneceriam fechadas nas suas linguagens especializadas. A compreensão recíproca que daí resultará é um dos fatores essenciais de melhor integração dos saberes, que Gomes (2001) salienta como necessidade de promover um diálogo partindo da identificação das disciplinas que alteram seus campos.

\section{(IN)CONCLUSÕES}

Os resultados apresentados neste estudo reforçam as caracterizações da CI como um campo de conhecimento interdisciplinar - não apenas pelas formações diversas dos alunos pesquisados, mas também pelas suas afirmações, sobretudo a respeito da busca pelos fundamentos teóricos da CI para trabalhar seus objetos de estudo. Porém, ainda precisam ser estudadas e identificadas as teorias e os métodos que mais favorecem o intercâmbio de conhecimentos e potencializam a interação entre as áreas e os pesquisadores dos diferentes domínios do conhecimento.

É importante destacar que esses pesquisadores, provenientes de outros campos, que vêm completar sua formação na CI, não apenas se apropriam dos conceitos, métodos e temáticas da CI, mas trazem suas próprias abordagens para construir as relações possíveis. Ou seja, sua inserção na CI não se dá de maneira passiva ou unidirecional. Eles se 
Desvelando a interdisciplinaridade da ciência da informação: o enfoque dos alunos do PPGCI/UFMG

socializam, integram em sua prática de pesquisa ideias e conceitos da CI, mas fazem isso interferindo, provocando e interpelando a CI, colocando novas perguntas e problemas, testando o limite das teorias e metodologias consolidadas.

Tal quadro aponta para a importância de se valorizarem as práticas de produção do conhecimento pautadas pela ideia da interdisciplinaridade e das potencialidades abertas para a CI com o estabelecimento de relações de troca e reciprocidade com os atores de outras áreas. Para tanto, é essencial que os mestrandos e doutorandos oriundos dessas áreas, uma vez "convertidos" em pesquisadores da CI, estabeleçam um diálogo efetivo para a consolidação das relações - ou seja, que não apenas busquem na CI métodos, conceitos e teorias para construir suas ideias e refletir sobre seus objetos de pesquisa. Cabe identificar não só as trilhas teóricas e metodológicas e o olhar da informação que a CI confere a estas áreas, mas também o que elas deixam de relacional para a CI.

Finalmente, os resultados obtidos, além de lançarem luz sobre os questionamentos iniciais norteadores deste trabalho, provocam novas inquietações: quais as concepções de interdisciplinaridade dos sujeitos de áreas diversas que dialogam com a CI? Como se dá a relação de reciprocidade entre a $\mathrm{CI}$ e essas áreas? $\mathrm{O}$ que os estudos conduzidos por esses pesquisadores podem trazer para a CI? Qual tem sido a efetiva contribuição das outras áreas para CI? As respostas a esses questionamentos suscitam, a posteriori, a realização de pesquisas, visando a contribuir para o fortalecimento teórico e metodológico da CI.

\section{AGRADECIMENTOS}

Agradecemos às professoras Rosa Zuleide Lima da Silva, Anna Elizabeth Galvão Coutinho Correia e Edna Gomes Pinheiro pela sua colaboração na elaboração deste trabalho.

Artigo submetido em 10/12/2008 e aceito em 06/05/2009.

\section{REFERÊNCIAS}

ADORNO, Theodor W.; HORKHEIMER, Max. Dialética do esclarecimento. Rio de Janeiro: Zahar, 1990.

ALFONSO-GOLDFARB, Ana Maria. O que é história da ciência. São Paulo: Brasiliense, 1994.

ALVES, Rubem. Filosofia da ciência: introdução ao jogo e suas regras. São Paulo: Brasiliense, 1982.

ARAÚJO, Carlos Alberto Ávila. et al. A Ciência da Informação na visão dos professores e pesquisadores brasileiros. Informação \& Sociedade: estudos, João Pessoa, v. 17, n. 2, p. 95-108, maio/ago. 2007. Disponível em: <http://www.ies.ufpb.br/ojs2/index.php/ ies/article/view/637/1450>. Acesso em: 15 dez. 2007.

BORKO, Harold. Information science: what is it? American Documentation, Washington, v. 19, n. 1, p. 3-5, Jan. 1968.

DAHLBERG, Ingetraut. Teoria do conceito. Ciência da informação, Rio de Janeiro, v. 7, n. 2, p. 101-107, jul./dez. 1978.

DELATTRE, Pierre. Investigações interdisciplinares: objectivos e dificuldades. In: POMBO, Olga; LEVY, Teresa; GUIMARÃES, Henrique (Org.). Antologia I: ciência integrada, interdisciplinaridade e ensino integrado das ciências. Lisboa: Mathesis, 1990. 177 p.

FOUREZ, Gérard. $A$ construção das ciências: introdução à filosofia e à ética das ciências. São Paulo: Unesp, 1995.

FRANÇA, Vera Regina Veiga. Do telégrafo à rede: o trabalho dos modelos e a apreensão da comunicação. In: PRADO, José Luiz Aidar (Org.). Crítica das práticas midiáticas: da sociedade de massa às ciberculturas. São Paulo: Hacker, 2002a. p. 57-76.

Paradigmas da comunicação: conhecer o quê? In: MOTTA, Luiz Gonzaga. et al. (Org.). Estratégias e culturas da comunicação. Brasília: UnB, 2002b. p. 13-29.

GOMES, Henriette Ferreira. Interdisciplinaridade e ciência da informação: de característica a critério delineador de seu núcleo principal. DataGramaZero - Ciência da Informaşão, v. 2, n. 4. ago. 2001.

GONÇALVES, Francisca dos Santos. Interdisciplinaridade e construção coletiva do conhecimento: concepção pedagógica desafiadora. 1991. Trabalho final apresentado à disciplina Ensino de ciências humanas história, geografia e sociologia. Faculdade de Educação/USP, São Paulo, 1991.

HABERMAS, Jurgen. Theory of communicative action. Boston: Beacon Press, 1987. 2 v.

JAPIASSU, Hilton. Interdisciplinaridade e patologia do saber. Rio de Janeiro: Imago, 1976.

; MARCONDES, Danilo. Dicionário básico de filosofia. 2. ed. Rio de Janeiro: Zahar, 1991. 265 p.

KRAGH, Helge. Introducción a la historia de la ciencia. Barcelona: Editorial Crítica, 1989. 
Alzira Karla Araújo da Silva / Izabel França de Lima / Carlos Alberto Ávila Araújo

LÉVY, Pierre; AUTHIER, Michel. As árvores de conbecimentos. São Paulo: Escuta, 1995.

MASLOW, A. As necessidades de conhecimento e o seu condicionamento pela mente e pela coragem. In: DEUS, Jorge Dias de (Org.). A crítica da ciência: sociologia e ideologia da ciência. Rio de Janeiro: Zahar, 1979. p. 206-218.

MORIN, Edgar. Política de civilização e problema mundial. Porto: [S. l.], 1996

MOSTAFA, Solange Puntel. Ciência da Informação: uma ciência, uma revista. Ciência da Informação, Brasília, v. 25, n. 3, 1996.

OMNÉS, Roland. Filosofia da ciência contemporânea. São Paulo: Unesp, 1996.

PAIM, Isis. Interdisciplinaridade. Belo Horizonte: ECI/UFMG, 2002.

PINHEIRO, Lena Vânia Ribeiro. Ciência da Informação: desdobramentos disciplinares, interdisciplinaridade e transdisciplinaridade. Rio de Janeiro: IBICT/MCT, 2002.

; LOUREIRO, José Mauro Matheus. Traçados e limites da Ciência da Informação. Ciência da Informação, Brasília, v. 24, n. 1, 1995.

POMBO, Olga. Contribuição para um vocabulário sobre interdisciplinaridade. In: POMBO, Olga; LEVY, Teresa; GUIMARÃES, Henrique (Org.). A interdisciplinaridade: reflexão e experiência. 2. ed. Lisboa: Texto, 1994.

Epistemologia da interdisciplinaridade. In: PIMENTA, Carlos (Coord.). Interdisciplinaridade, bumanismo universidade. Porto: Campo das Letras, 2003. Disponível em: <http:// www.educ.fc.ul.pt/docentes/opombo/investigacao/ portofinal.pdf $>$. Acesso em: 28 mar. 2008.
SANTOS, Boaventura de Sousa. Um discurso sobre as ciências. São Paulo: Cortez, 2003.

SARACEVIC.Tefko. Introduction to information science. New York: R. R. Bowker, 1970.

Ciência da informação: origens, evolução e relações. Perspectivas em Ciência da Informação, Belo Horizonte, v. 1, n. 1, p. 41-62, jan./jun. 1996.

Introduction to information science. New York: Bowker, 1970.

SERRES, Michel. Elementos para uma história das ciências. Lisboa: Terramar, $1989.3 \mathrm{v}$.

SMIT, Johanna W.; TÁLAMO, Maria de Fátima G. M.; KOBASHI, Nair Y. A determinação do campo científico da Ciência da Informação: uma abordagem terminológica. DataGramaZero Ciência da Informação, v. 5, n.1, fev. 2004. Disponível em: <http:// www.dgz.org.br/fev04/Art_03.htm>. Acesso em: 3 mar. 2006.

SOUZA, Francisco das Chagas. Interdisciplinaridade da Ciência da Informação. In: PINTO, Virgínia Bentes; CAVALCANTE, Lídia Eugenia Cavalcante; SILVA NETO, Casemiro (Org.). Ciência da Informação: abordagens transdisciplinares gêneses e aplicações. Fortaleza: Edições UFC, 2007.

TARGINO, Maria das Graças. A interdisciplinaridade da Ciência da Informação como área de pesquisa. Revista Informação \& Sociedade: Estudos, João Pessoa, v. 5, n. 1, p.12-17, jan./dez. 1995. 